We thank Laporte Titanium, Ltd., for their co-operation, and Dr. S. H. Ayliffe for permission to publish this communication.

\section{Bristol College of Science} and Technology.

${ }^{2}$ Förland, K. S., Intern. Symp. Reactivity of Solids, Gothenburg (1952). 'Cronemeyer, D. C., and Gilles, M. A., Phys. Rev., 82, 975 (1951). ${ }^{3}$ Rees, A. L. G., Chemistry of the Defect Solid State (Methuen, 1954). ${ }^{4}$ Weyl, W. A., and Förland, T., Indust. Eng. Chem., 42, 257 (1950). "Sandler, Y. L., J. Phys. Chem., 58, 54 (1954).

${ }^{6}$ Gray, T. J., McCain, C. C., and Masse, N. G., J. Phys. Chem., 63, 472 (1959).

'Whalley, E., and Winter, E. R. F., J. Chem. Soc., 1175 (1950).

${ }^{8}$ Vondjidis, A. G., and Clark, W. C. (to be published).

\section{METALLURGY}

\section{$250^{\circ} \mathrm{C}$ Internal Friction Peak in Iron}

We read with interest the communication by Rosenfield ${ }^{1}$ regarding the $250^{\circ} \mathrm{C}$ internal friction peak in iron, and would like the opportunity of commenting on the inferences and conclusions made in it. Previous work by Köster et al. ${ }^{2}$, more recently confirmed by Petarra ${ }^{3}$, has established a unique relationship between the Snoek peak $\left(43^{\circ} \mathrm{C}\right.$ for $\left.\sim 1 \mathrm{c} / \mathrm{s}\right)$ and the $250^{\circ} \mathrm{C}$ peak for the cases of dilute iron-nitrogen and dilute iron-carbon alloys. A dependence $\theta^{2}$ of the $250^{\circ} \mathrm{C}$ peak height on the degree of deformation, and therefore on the dislocation density in the specimen, was also found for these alloys. Unpublished work in this Department on the $250^{\circ} \mathrm{C}$ peak has shown that either carbon or nitrogen or both elements are essential for the appearance of the peak. Furthermore, after a decarburization treatment, specimens of pure iron showed no evidence at all of a $250^{\circ} \mathrm{C}$ peak on subsequent testing. This treatment (moist hydrogen) could certainly have introduced oxygen into the specimens.

The solubility of oxygen in the lattice is so small that no Snoek peak is observed in annealed and quenched iron specimens which might be expected to have oxy'gen present in solution if this were possible. These are partially the conditions for observation of the Köster peak. The observed effect of cold work on the Snoek peak, for carbon and nitrogen in iron, is to reduce the peak height ${ }^{4}$. Thus, if the $250^{\circ} \mathrm{C}$ peak were due to oxygen in solution then the peak in the undeformed material might be even bigger. The assumption has been made that oxygen would be interstitial in the iron lattice. The activation energy suggested by Rosenfield, $28 \mathrm{kcal} / \mathrm{mol}$, is the value associated with interstitial atoms. However, there is no evidence that oxygen occupies interstitial sites in the iron lattice and in fact its ion size might suggest substitutional solution, in which case the activation energy for diffusion would be expected to be about $60-70 \mathrm{kcal} / \mathrm{mol}$.

Other workers ${ }^{5,6}$ have measured activation energies for the Köster peak varying from 32 to $35 \mathrm{kcal} / \mathrm{mol}$.; while this agrees with Köster's original explanation his mecha. nism must bo in doubt when it is realized that long times are needed for the peak to become measurable. Our results suggest that the probable cause of the Köster peak is associated with fine precipitates of iron carbide interacting with the dislccation networks, thus tending to anchor them when elastic stresses are applied. It is possible that in the early stages of ageing a number of processes are taking place very quickly, each having different relaxation times, producing a general rise in background damping over a range of temperature. The slow formation of the $250^{\circ} \mathrm{C}$ peak must then be a result of these ageing processes.

P. BARRAND

G. M. LEAK

Department of Metallurgy,

University of Manchester.
${ }^{1}$ Rosenfield, A. R., Nature, 196, 1083 (1962).

${ }^{2}$ Köster, W., Bangert, L., and Hahn, R., Archiv. Eisenhilttenw., 25, 569 (1954).

3 Petarra, D. P., thesis, Columbia Univ, (1962).

-Thomas, W. R., and Leak, G. M., J. Iron and Steel Inst., 180, 155 (1955).

' Kaddou, Abdul-Fattah K., and Rosenthal, P. C., Trans. Amer. Soc. Met., $52,116(1960)$.

${ }^{6}$ Kamber, K., Keefer, D., and Wert, C., Acta Met., 9, 403 (1961).

Barrand and Leak have criticized my recent suggestion that the $250^{\circ} \mathrm{C}$ internal-friction peak in iron is due to the effects of oxygen in solution. Their criticism is based on two arguments: a postulated relation between carbon and/or nitrogen in solution and the low solubility of oxygen in iron.

In defending the first argument, the claim was made that there is a "unique relationship between the Snoek peak and the $250^{\circ} \mathrm{C}$ peak for the cases of dilute ironnitrogen and dilute iron-carbon alloys". The experimental evidence on this point does not reveal such a relation. In the experiments of Köster et al. ${ }^{1}$ there was, indeed, a linear dependency of the height of the $250^{\circ} \mathrm{C}$ damping peak $\left(\delta_{H}\right)$ and the $40^{\circ} \mathrm{C}$ damping peak $\left(\delta_{L}\right)$ under certain conditions. Under other conditions, however, $\delta_{L}$ varied by as much as an order of magnitude with no perceptible change in $\delta_{H}$ (for example, when $\delta_{H}=3 \times 10^{-3}, \delta_{L}$ varied between $4 \times 10^{-3}$ and $37 \times 10^{-3}$ ). The results of Petarra ${ }^{2}$ on specimens of various interstitial contents deformed. 14.8 per cent are shown in Fig. 1. Here, too, under certain conditions $\delta_{H}$ is directly proportional to $\delta_{L}$, although the slope is different from that of Köster et al. Furthermore, in these data for $\delta_{L} \approx 12 \times 10^{-3}$, $\delta_{H}$ varies by more than an order of magnitude. Both these results clearly suggest that there is at least one additional independent variable controlling $\delta_{H}$.

To bolster the first argument further, Barrand and Leak claim that "either carbon or nitrogen or both elements are essential for the appearance of the peak". It is not clear whether they mean carbon and nitrogen in solution (that is, those carbon and nitrogen atoms which can be detected by internal friction in contrast to carbon and nitrogen atoms bound to dislocations or in precipitates, which cannot be detected by internal friction). That carbon and/or nitrogen in solution is not necessary is indicated by the data shown in Fig. 1, which contains two points where $\delta_{H}$ was measurable when $\delta_{L}$ was zero, and several others where $\delta_{L}$ was barely perceptible $\left(\sim 10^{-3}\right)$.

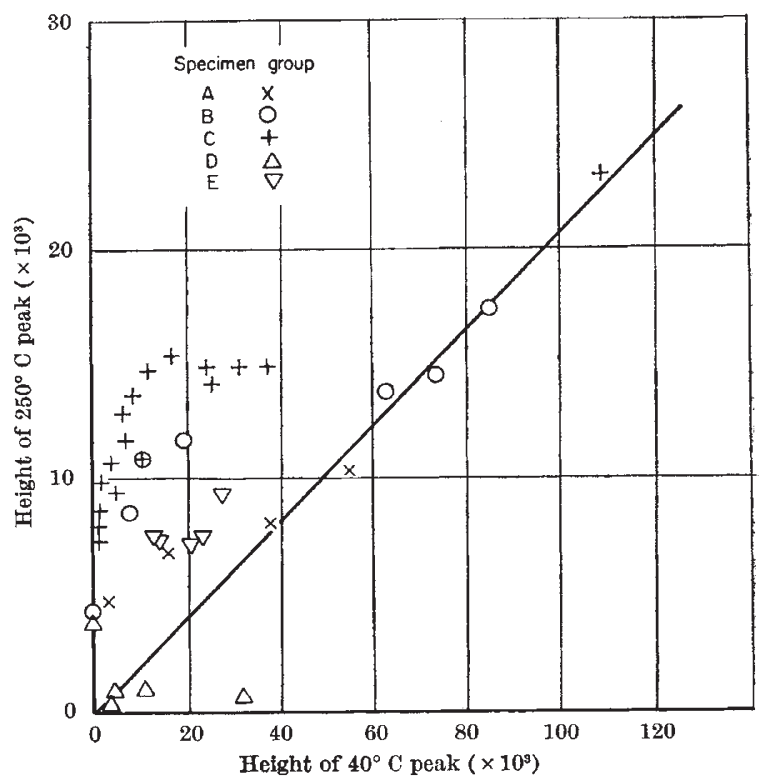
Fig. 1. Simultaneous measurements of $250^{\circ} \mathrm{C}$ peak and $40^{\circ} \mathrm{C}$ peak 